\title{
Supporting Carers through Intelligent Technology
}

\author{
Kirsten Smith \\ University of Aberdeen \\ Computing Science \\ Aberdeen, AB24 3UE \\ r01kas12@abdn.ac.uk
}

\begin{abstract}
Informal carers lack adequate practical and emotional support. This $\mathrm{PhD}$ investigates how a software agent could be used to help maintain a carer's personal social network by mediating communication and facilitating the provision of emotional and practical support. The agent should use features of the carer and their social network to provide a personalized support interface.
\end{abstract}

\section{Author Keywords \\ Emotional Support; Agents; EHealth; Social Networks}

\section{ACM Classification Keywords}

H.1.2. User/Machine Systems

\section{INTRODUCTION}

Informal carers provide regular personal physical or mental support for their caree who could not manage without them, saving the UK economy $£ 119$ billion per year [1]. Carers are much more likely than the general population to report poor health $[3,16]$. Support is essential to enable them to continue to provide care without impacting on their own quality of life. We propose a solution that facilitates mediated asynchronous communication between the carer and their personal social network, using an intelligent agent to identify and offer support.

\section{BACKGROUND LITERATURE}

\section{Social Network Theory.}

Studies of personal social networks [7] tell us that an individual (ego) has several distinctive bands of friendships of a constant size (see Figure 1). This interacts with factors such as income, marriage \& personality [13, 8]. Without network maintenance a friendship will degrade; thus, if an individual is not able to invest time in network maintenance they may lose friends [13]. Individual differences in social network imply that certain people may prefer to broadcast their situation on an open forum while others prefer to use individual private messages to friends [8].

Permission to make digital or hard copies of part or all of this work for personal or classroom use is granted without fee provided that copies are not made or distributed for profit or commercial advantage and that copies bear this notice and the full citation on the first page. Copyrights for third-party components of this work must be honored. For all other uses, contact the owner/author(s).

Copyright is held by the author/owner(s)

IUI'14 Companion, February 24-27, 2014, Haifa, Israel.

ACM 978-1-4503-2729-9/14/02.

http://dx.doi.org/10.1145/2559184.2559192
Identifying the different layers of social network will allow a software agent to offer a different quality of mediated communication to close and distant friends, found to be effective for neo-natal care infant parents [10]. It is also important in identifying frequency of contact required for effective network maintenance.

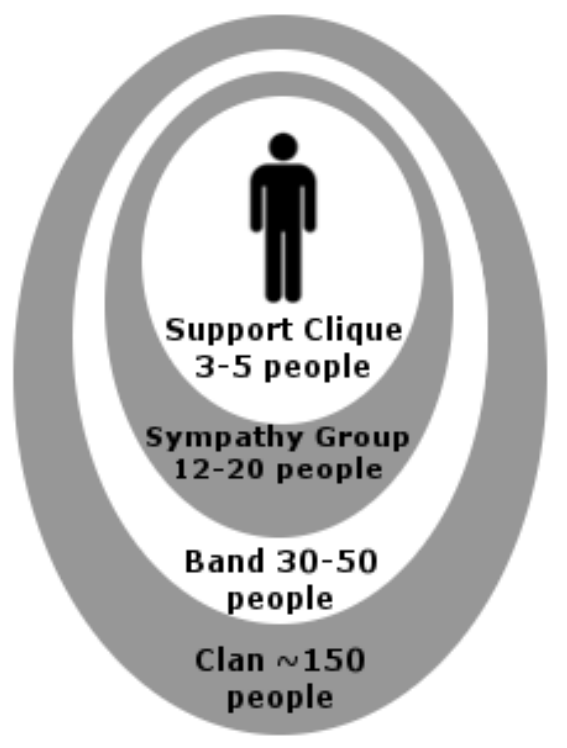

Figure 1. Layers of an ego's social network [7]

\section{E-health Support Systems}

Several systems have already been implemented that show that online support for patients and their carers is effective. Many of these have been disease-specific discussion boards $\&$ information pages $[11,15]$. Others facilitate mediated communication between a personal social network to obtain support or practical help (e.g. in the domain of neonatal care [10]) though there is no research in the domain of carers.

\section{Emotional Support}

Effective emotional support messages are person-centred (PC) - they acknowledge and accept feelings and elaborate on their meaning [2]. This type of emotional support feedback has been found to be effective given by text-based interactive support agents for stressful computer problems [9]. It is important to take into account the user's feelings, personality traits, situation or other demographic variables when offering emotional support - students with failing 
grades are given different feedback depending on conscientiousness [4] and agents that react to users' affective state reduces stress following frustration [12].

We aim to find out the type of emotional support that is appropriate and effective for carers in different stressful situations, and adapt this to them given demographic variables, affective state \& feedback on the efficacy of previous support messages. We aim to link this support with suggestions of contacting suitable members of their social network (adaptive to user ratings, friend availability and feedback) to gain appropriate practical/emotional support.

\section{THE PROBLEM OF SUPPORT}

We can broadly divide types of support into three categories - informational, emotional and practical. Informational support entails the provision of knowledge and skills that facilitate problem solving. Emotional support entails empathy and reassurance, reinforcing the individual's self-worth. Practical support is the provision of material or assistance to solve a problem [14]. Current support provision is summarized in Table 1.

\begin{tabular}{|l|l|l|}
\hline \multirow{2}{*}{$\begin{array}{l}\text { Support } \\
\text { type }\end{array}$} & \multicolumn{2}{|l|}{ Support Provision } \\
\cline { 2 - 3 } & Offline & Online \\
\hline Informational & $\begin{array}{l}\text { Local healthcare; } \\
\text { Carer support } \\
\text { charities }\end{array}$ & $\begin{array}{l}\text { Static healthcare } \\
\text { websites }\end{array}$ \\
\hline Emotional & $\begin{array}{l}\text { Local carer support } \\
\text { groups; } \\
\text { Family and friends }\end{array}$ & $\begin{array}{l}\text { Online } \\
\text { discussion } \\
\text { boards }\end{array}$ \\
\hline Practical & $\begin{array}{l}\text { Charity respite; } \\
\text { Professional carers }\end{array}$ & N/A \\
\hline
\end{tabular}

Table 1. Current carer support provision

We focus on emotional support. Carers have limited availability to leave their caree and attend support sessions, socialise with friends or complete out of house tasks such as shopping. They may themselves have impaired health and lack access to transport at times when they are free. While asynchronous emotional support is available on discussion boards, this form of interaction is not suitable for all. Social isolation and degradation of social ties due to the lack of interaction [13] exacerbates the dearth of emotional support and contributes to a lack of practical support for carers.

We propose that a carer's quantity and quality of emotional support will vary greatly with demographic variables (e.g. rural living, marital status, income, age) as well as personality. These variables should be taken into account when tailoring emotional support.

\section{PROPOSED SOLUTION}

Imagine this scenario:

Helen cares for her husband Rob, who has Alzheimer's Disease and cannot be left alone for more than an hour.
One day Rob is particularly upset and Helen doesn't want to leave him to collect his prescription from the pharmacy. She wants to ask for help from close friends who live nearby but not alarm her frail mother-in-law of Rob's distress. She is quite stressed and would like someone to talk to.

In this scenario, the agent would create a request to nearby close members of Helen's network for her. It would offer some appropriate adaptive emotional support through a conversational interface and suggest a remedial action based on Helen's preferences and the network availability for instance, phone your sister.

\section{RESEARCH QUESTIONS}

- How can an intelligent agent effectively facilitate mediated communication between carers and their personal social network?

- How can this facilitation be adapted to an individual carer (e.g., circumstances, personality)?

- How can an intelligent agent deliver emotional support to carers in distressing circumstances?

\section{METHODOLOGY}

We shall use an agile approach. Initially, qualitative methods (e.g. focus groups) and surveys will be used for knowledge acquisition, principally with carers. Experiments will be conducted to develop a model of tailored mediated communication and computer-based emotional support before prototypes are developed. We will then trial our prototypes with carers and their social networks and assess their usage \& satisfaction through both qualitative and quantitative measures. This will allow us to refine, adjust \& re-evaluate our model.

\section{ONGOING WORK}

\section{Focus Groups \& Interviews}

We are currently recruiting participants for a series of focus groups and interviews with carers. The aims of these groups are to find out how carers use technology, how they communicate with their friends, how they plan their time and who they ask for help. This will help direct us to the most important type of features in an application for carers, which can then be evaluated through further studies.

\section{Social Network Interaction Study}

We have designed a study to discover how the demands of caring affect the quality and quantity of interactions with friends and family. We hope to discover how demographic variables (e.g. hours of care/week, rural/city location, transport availability) affect the quality and quantity of interactions with their close and distant friends compared with their desired level of interaction. This will help us to identify how aspects of caring responsibilities affect the ability to maintain relationships while also revealing the desired quality of interaction that carers want. 


\begin{tabular}{|c|c|}
\hline Stressor & Scenario \\
\hline $\begin{array}{l}\text { Mental } \\
\text { Demand }\end{array}$ & $\begin{array}{l}\text { Martin is Julia's carer. Today Martin had to carry out minor medical tests. The tests are not dangerous if he does } \\
\text { them wrong but the procedure is complex and requires concentration. }\end{array}$ \\
\hline $\begin{array}{l}\text { Temporal } \\
\text { Demand }\end{array}$ & $\begin{array}{l}\text { Ben is Samantha's carer. Today Ben had to drop Samantha off at the doctors at } 4.30 \mathrm{pm} \text {, collect her prescription from } \\
\text { the pharmacy at the other side of town before it closed and collect some groceries before collecting her at } 5 \mathrm{pm} \text {. }\end{array}$ \\
\hline $\begin{array}{l}\text { Physical } \\
\text { Demand }\end{array}$ & $\begin{array}{l}\text { Carol is Max's carer. Today Carol moved heavy furniture and boxes from Max's upstairs bedroom to his new } \\
\text { bedroom downstairs. }\end{array}$ \\
\hline Frustration & $\begin{array}{l}\text { Harry is Diane's carer. Today Harry wanted to drop Diane off at the day care center so he could have some free time, } \\
\text { but the center was closed. }\end{array}$ \\
\hline Interruption & Susan is John's carer. Today Susan needed to get John ready for bed, but people kept phoning her. \\
\hline $\begin{array}{l}\text { Emotional } \\
\text { Demand }\end{array}$ & Andrea is Gary's carer. Today Gary was confused and very upset and Andrea comforted him. \\
\hline Isolation & $\begin{array}{l}\text { Fiona is Fred's carer. Fred spends most of the day asleep. Today Fiona was alone all day and no home carers were } \\
\text { scheduled to visit. }\end{array}$ \\
\hline
\end{tabular}

Table 2. Validated Scenarios depicting Carers in Different Stressful Situations

\section{Emotional Support Statement Study}

Using the methodology of [5], we have developed and validated a series of scenarios that depict carers in various stressful situations (see Table 2), developing an approach we used for first responders [6].

We then used these scenarios to collect a bank of emotional support statements that people would give a carer in different situations. We have categorized these statements into different types and are evaluating their efficacy, helpfulness and appropriateness for the different scenarios, as well as for different personality and demographic variables of the carer in the scenario. We will then have effective adaptive emotional support statements that an agent could use at different times of stress.

\section{ACKNOWLEDGEMENTS}

This $\mathrm{PhD}$ is funded by the Northern Research Partnership.

\section{REFERENCES}

1. Buckner, L. \& Yeandle, S. Valuing carers 2011 (2011) London: Carers UK.

2. Burleson, B. R. Comforting messages: Features, functions, and outcomes. In J. A. Daly, \& J. M. Wieman (Eds.), Strategic interpersonal comm. (1994) 135-161

3. Census 2001. Office for National Statistics. (2001)

4. Dennis, M. et al. Does Learner Conscientiousness Matter when Generating Emotional Support in Feedback? 2013 Affective Comp. \&Intell. Interaction. (2013) 209-214

5. Dennis, M. et al. The quest for validated personality trait stories. Proceedings of the 2012 ACM Int. Conf. on Intell. User Interfaces (2012) 273-276

6. Dennis, M. et al. Towards effective emotional support for community first responders experiencing stress. 2013 Affective Comp. \& Intell. Interaction (2013)
7. Hill, R. \& Dunbar, R. Social network size in humans. Hum.Nat.Interdiscip.Biosoc.Perspect. 14(1)(2003) 5372

8. Kalish, Y. \& Robins, G. Psychological predispositions and network structure: The relationship between individual predispositions, structural holes and network closure. Soc.Networks, 28(1)(2006) 56-84

9. Klein, J. et al. This computer responds to user frustration: Theory, design, and results. Interact. Comput. 14(2)(2002) 119-140

10. Moncur, W. et al. Providing adaptive health updates across the personal social network. HCI.(2013) 1-56

11. Namkoong, $\mathrm{K}$. et al. Creating a bond between caregivers online: Effect on caregivers' coping strategies. J.Health Commun., 17(2)(2012) 125-140

12.Prendinger, H. \& Ishizuka, M. The empathic companion: A character-based interface that addresses users' affective states. Appl.Artif.Intell., 19(3-4)(2005) 267-285

13. Roberts, S. \& Dunbar, R. The costs of family and friends: An 18-month longitudinal study of relationship maintenance \& decay. Evol.Hum.Behav. 32(3)(2011) 186-197

14. Sit, J. et al. Stroke care in the home: The impact of social support on the general health of family caregivers. J.Clin.Nurs., 13(7)(2004). 816-824

15. Smith, G. C. et al. Reducing depression in stroke survivors and their informal caregivers: A randomized clinical trial of a web-based intervention. Rehabil.Psychol. 57(3)(2012). 196-206

16. Vitaliano, $P$. et al. Is caregiving hazardous to one's physical health? A meta-analysis. Psychol.Bull, 129(6)(2003) 946-972 